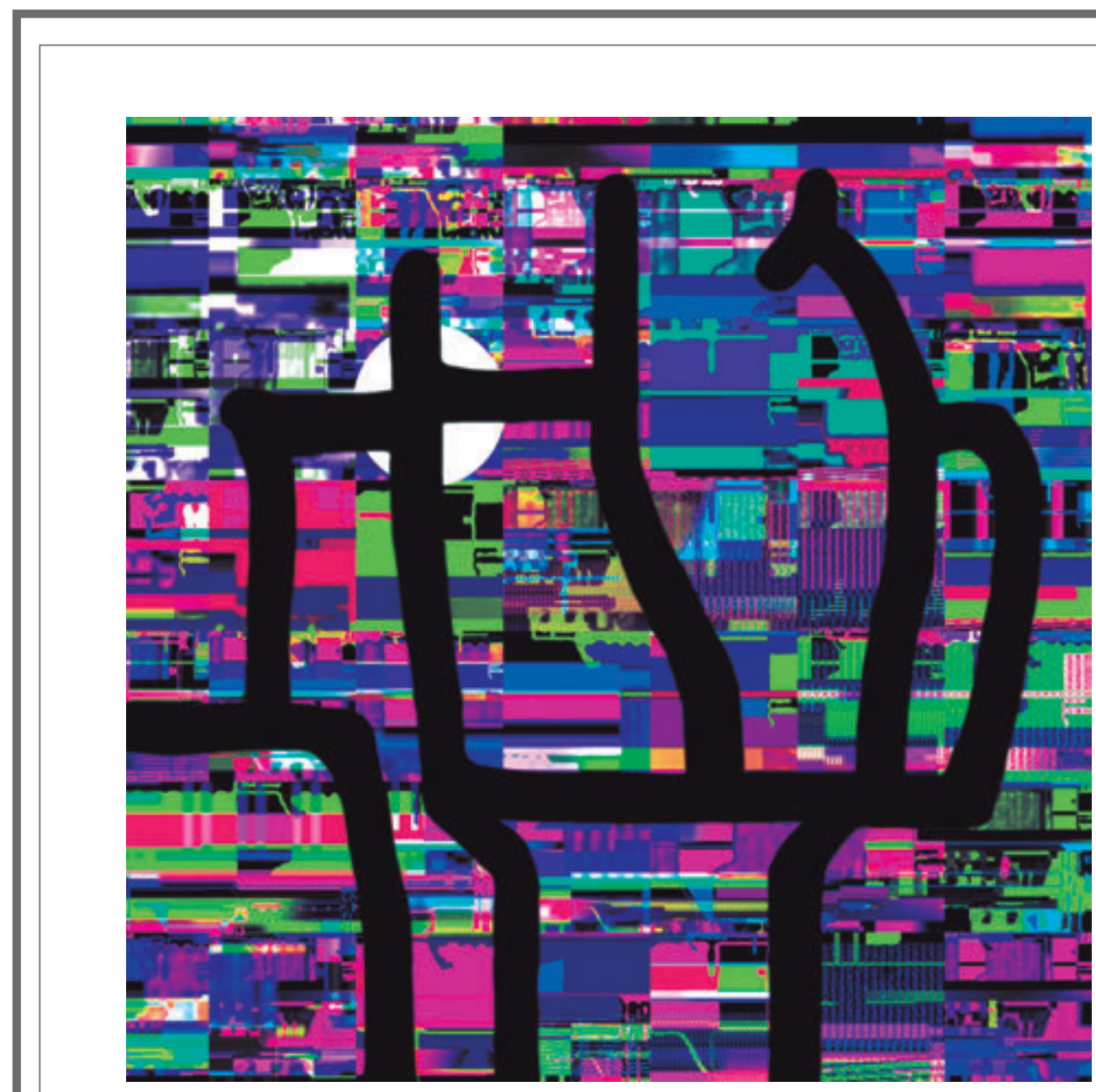

Estampa Digital

Arquitectura 10 P.M. 


\section{Autor:}

Luis Fernando Luna

Técnica:

Impresión Digital Giclée sobre papel de Algodón 255 gr.

Medida: 40 X $40 \mathrm{~cm}$ (Estampa 30 X $30 \mathrm{~cm}$ )

Edición de 25 ejemplares 


\title{
COLOMBIA Y VENEZUELA: DOS ORILLAS OPUESTAS DE LA ALDEA GLOBAL EN LA ERA POST- CAÍDA DEL MURO DE BERLÍN
}

\section{COLOMBIA AND VENEZUELA: TWO OPPOSITE SIDES OF THE GLOBAL VILLAGE AFTER FALLING THE BERLIN WALL}

Julio Ramírez Montañez

\begin{abstract}
Resumen
En las décadas posteriores a la caída del muro de Berlín, cuando se generalizó el concepto de globalización de la economía, la mayoría de los estudiosos de las relaciones internacionales abordaron el tema a partir del supuesto de una relativa unificación de los principios que regularían el sistema mundial en la búsqueda de objetivos comunes. Sin embargo, en el escenario político-económico actual se superponen contradicciones y acuerdos, hecho que hace, cada vez, más lejana la idea de la Aldea Global. Así, el objetivo fundamental del artículo es analizar las diferencias en la política exterior de Colombia y Venezuela durante las últimas décadas, e indagar sobre los presupuestos ideológicos que las soportan, como paso previo a la formulación de un proyecto de investigación que pretende evaluar el impacto de esta política en las relaciones económicas entre los dos países.
\end{abstract}

\section{Palabras Clave:}

Aldea Global, Respice Polum, Respice Similia, Política exterior, Colombia, Venezuela.

\begin{abstract}
In the decades after the fall of the Berlin Wall, when the concept of globalization of the economy was generalized, most international relations scholars approached the subject from the assumption of a relative unification on the principles that regulate the world system in pursuit of common objectives. However, in the political-economic scenario contradictions and current arrangements are overlapped doing more and more distant the idea of the Global Village. Thus, the primary objective of this paper is to analyze the differences in foreign policy of Colombia and Venezuela over the past decades, and to inquire about the ideological assumptions that support them, prior to the formulation of a research project which seeks to assess the impact of this policy on economic relations between two countries.
\end{abstract}

\section{Key Words}

Global Village ‘,' Respice Polum ‘,' Respice Similia ‘, Foreign Policy, Colombia, Venezuela. 


\section{Introducción}

Desde las últimas décadas del siglo pasado, se ha generado una restructuración geopolítica en todo el mundo, alentada por el final de la guerra fría, el surgimiento de nuevos actores económicos en el escenario mundial y el impacto creciente de las tecnologías de la comunicación que han derribado las barreras físicas e impulsado el fenómeno conocido como globalización de la economía. Sin embargo, la profecía de McLuhan de una 'aldea global' homogénea y estandarizada en procesos, estructuras políticas, ideologías y pautas de consumo, dista mucho de ser una realidad en los albores del siglo XXI. Se podría afirmar que, en algunos casos, resultan más evidentes las paradojas que las coincidencias, las tensiones que los acuerdos y los focos de conflicto que el bucólico mundo al que hace referencia la imagen del gran maestro de las comunicaciones.

Para ilustrar la afirmación precedente, el objetivo primordial del presente artículo es presentar un breve análisis de los procesos y las estrategias disímiles desarrolladas por Colombia y Venezuela en el periodo histórico post-caída del muro de Berlín (19902011), dentro del marco conceptual de la "aldea global". Se busca una aproximación al sistema político y económico de Colombia y Venezuela durante ese período, donde se han producido interacciones y demandas doméstico-globales diferentes, las cuales han sido afrontadas desde dos perspectivas opuestas. La hipótesis es que Colombia y Venezuela utilizan estrategias de política exterior totalmente inversas, hacia el logro de una inserción positiva dentro del escenario globalizado.

En esa mirada, se observa una dinámica diferente de los dos países, no sólo frente a la discusión de temas relevantes como la soberanía nacional y el papel de los organismos multilaterales, sino también en lo que tiene que ver con la integración continental y la aplicación del sistema democrático de la OEA. Pero, dentro de esas estrategias que aparecen como divergentes, resalta la posición que han adoptado los dos países en sus relaciones con los Estados Unidos. Es evidente que los discursos y las acciones en materia de relaciones exteriores responden, de manera directa, a las transformaciones y continuidades observadas en la orientación de las relaciones entre este último país y el resto del mundo, en las diferentes fases del proceso globalizador.

Colombia históricamente ha utilizado una estrategia de Réspice Polum (mirar al polo o mirar al norte) a ultranza, basada en su dependencia y subordinación a los Estados Unidos, en la que el país había encontrado, hasta ahora, la garantía de su supervivencia en lo económico, político y militar, con algunos cortos períodos caracterizados por la búsqueda de autonomía relativa (Ramírez, 2003). Sin embargo, con la llegada de Juan Manuel Santos a la Presidencia de Colombia, la estrategia internacional del Estado colombiano da un giro inesperado y se da inicio a una nueva era de inserción internacional, dándole preponderancia a una doctrina de afianzamiento de la relación con el vecindario en Latinoamérica y en el Pacifico, manteniendo una línea de continuidad en lo que se refiere a las relaciones con Estados Unidos. 
Por su parte, Venezuela desde la llegada al poder del coronel Hugo Chávez Frías, ha puesto en práctica una estrategia de Respice Similia (mirar a los semejantes) sobre la base del liderazgo ejercido hacia la construcción de un bloque regional con algunos "Estados similares", al interior de la llamada Alternativa Bolivariana para América (ALBA) y bajo los lineamientos políticos de la llamada Revolución del Siglo XXI. En otros hemisferios, la política exterior de la Republica Bolivariana de Venezuela ha estado dirigida hacia el acercamiento con países como Rusia, China e Irán, los cuales son los proveedores del gran armamento adquirido por el ejército venezolano durante los últimos años.

Estos rumbos diferentes que tomaron Colombia y Venezuela, a pesar de ser naciones hermanas por contar con el mismo origen histórico, político, militar, étnico, cultural y religioso, durante los periodos de gobierno de los Presidentes Hugo Chávez y Álvaro Uribe, produjeron un nuevo campo de tensión ideológica, política y militar, similar al que se produjo durante la guerra fría, entre Alemania Oriental y Occidental o entre Vietnam del Norte y Vietnam del Sur o la que persiste hoy entre Corea del Norte y Corea del Sur. Así las cosas, estos procesos parecen mostrar un desplazamiento del eje de disputa entre capitalismo y socialismo hacia la Región Andina y, más específicamente, a las dos orillas que separan los Ríos Táchira y Arauca, en las que hoy en día, se da la común convivencia entre estos dos sistemas políticos y económicos.

El artículo se inicia con una serie de opiniones sobre el concepto de aldea global y hace énfasis en el periodo posterior a la caída del muro de Berlín. A continuación, se realiza un análisis de las dos estrategias de Respice Polum y Respice Similia' desarrolladas por Colombia y Venezuela para, finalmente, presentar algunas conclusiones y recomendaciones con el objetivo de ampliar la discusión acerca de los procesos que es necesario incentivar con miras al mejoramiento continuo -y duradero en el tiempo- de las relaciones Colombo-Venezolanas.

\section{Las Relaciones Internacionales: campo de debate}

Las relaciones internacionales constituyen un campo de estudio sumamente amplio, toda vez que allí confluyen factores de orden económico, jurídico, político e ideológico.

Desde la época de conformación de los Estados nacionales, las relaciones entre países y los interrogantes acerca de las causas de los conflictos y las condiciones para la paz, han formado parte de un debate académico inacabado en el que se entrecruzan las perspectivas de la Ciencia Política, la Historia y el Derecho Internacional y, más recientemente, de la Economía (Mesa, 1977). En la mayoría de enfoques que han pretendido explicar el fenómeno, entre los que sobresale el realismo clásico, se parte del supuesto que los Estados actúan según la lógica del “interés nacional” y sus 
reacciones están condicionadas por un sistema internacional, cuyas transformaciones actúan más sobre las características de la política exterior que las mismas condiciones políticas internas.

Ese debate se ha renovado en los últimos años con la inclusión en la lista de actores protagónicos que trascienden las fronteras nacionales, de las organizaciones multilaterales, los bloques de países o las corporaciones económicas multinacionales y con la consideración de problemáticas complejas como el calentamiento global, el respeto de los derechos de las minorías o la pobreza creciente. Lo cierto es que, hoy más que nunca, puede decirse que las relaciones internacionales continúan sometidas a una multiplicidad de puntos de vista que pueden pensarse, más como aproximaciones conceptuales que como teorías acabadas. Por eso mismo, preferimos referirnos en este trabajo al concepto más acotado de política exterior, que hace relación a las relaciones entre Estados sin considerar el entramado de intereses que están en juego a nivel internacional. Se parte entonces, del concepto de Del Arenal, quien considera que la política exterior no consiste en una mera sucesión o yuxtaposición de actitudes inconexas, sino que su existencia se define por la coherencia y la continuidad que guardan esas actitudes entre sí. (Del Arenal, 2005).

De alguna forma, aún a pesar de los condicionamientos externos, la política exterior puede considerarse como la extensión -en el plano ideológico- de la política interna. En ese contexto, resulta útil acercarse, tenida como referente la construcción histórica de la relación binacional, a la visión de política exterior de Colombia y Venezuela en los últimos años, especialmente porque su análisis puede ilustrar sobre la categoría, cada vez más compleja, de sistema internacional y sobre el papel jugado por los Estados Unidos frente al resto del mundo.

\section{De los Estados Nacionales a la Aldea Global}

Existen múltiples interpretaciones sobre el concepto de 'aldea global', todas ellas enmarcadas dentro de parámetros ideológicos, políticos y culturales diferentes. El concepto fue introducido por Marshall MacLuhan (1967) para hacer referencia al impacto de las innovaciones en los medios de comunicación de su época y, en su perspectiva, la aldea global podía definirse como el "estadio de interacción y cohesión planetaria de la conciencia humana, donde el tiempo se comprime y el espacio se achica". Por no conocer la Internet ni la revolución de las tecnologías de información y comunicación, sus análisis resultaron proféticos.

Por su parte, Charles Hill (2008) considera que la 'aldea global', tal y como la conocemos hoy en día, hace parte de un proceso que se desarrolla a la par de tres revoluciones industriales, siendo la del Reino Unido en 1850 la génesis de esta tendencia creciente a la profundización de la interdependencia económica, cultural y política entre las distintas regiones del mundo. Para este autor, el comercio internacional ha tenido, a su vez, tres etapas históricas de vital dinamismo en las que 
el desarrollo de las actividades en el campo de los negocios internacionales ha crecido más que en cualquier otro periodo de la humanidad. Estos periodos históricos son:

- $\quad$ 1870-1914 (La bella Época)

De acuerdo con el autor mencionado, este periodo tiene la característica principal de recoger el pensamiento económico de la época, encabezado por la corriente librecambista desarrollada por quien es considerado el padre de la economía y del comercio internacional como áreas científicas, Adam Smith. Es denominado por algunos expertos como la era dorada del comercio mundial por presentarse importantes desarrollos en el campo del transporte internacional y considerables reducciones en las tarifas arancelarias en el ámbito internacional. En este periodo, el Reino Unido se posiciona como la potencia hegemónica del mundo. (Hill, 2008)

- $1945-1990$

Para Hill, después de una etapa de caos, debido a las dos guerras mundiales y a la Gran Depresión de los años 30, la economía mundial vuelve a encarrilarse en un proceso de desarrollo e internacionalización gracias a la creación de las instituciones de Bretton Woods como el Fondo Monetario Internacional, el Banco Mundial y el GATT (Acuerdo General de Aranceles y Comercio).

- $\quad 1990-2011$

Las relaciones internacionales experimentan cambios fundamentales durante este período y se altera sustancialmente el escenario en el que las economías nacionales se encontraban relativamente aisladas, en primera instancia por barreras que impedían el comercio y la inversión internacional, pero también por obstáculos espaciales, temporales y lingüísticos y por las diferencias nacionales en torno a las regulaciones gubernamentales, especialmente en materia de mercados. La cultura y las creencias religiosas e ideológicas y los sistemas rectores de los negocios, ahondaban más la brecha, según plantea el autor que se reseña. (Hill, 2008)

\section{Interdependencia Global}

Palomares (2006) señala que la permanente transformación del sistema internacional afecta a toda la sociedad e introduce cambios en las dinámicas que vinculan de forma interdependiente a los nuevos actores de la escena internacional como son: la globalización, el conflicto, la integración y la cooperación. Son múltiples las fuentes de cambio en el mundo contemporáneo. De una parte, el impacto de la revolución tecnológica en curso que ha alterado, decididamente, la forma en que se producen bienes y servicios, así como el modo en el que se comercializan y se consumen y, en consecuencia, los enfoques sobre la gerencia en el nuevo contexto de los negocios. Adicionalmente, en el orden internacional se hanpresentado recomposiciones geopolíticas de enorme magnitud, que conducen a 
un reordenamiento del esquema básico en el que se desarrolló la historia del siglo pasado.

Para Person (2006) en la era actual, el mundo se ha hecho más intrincado, tanto en el campo doméstico como en el externo, como resultado del cambio y la mayor complejidad de las estructuras políticas y económicas, que tuvieron origen en las reformas emprendidas por Mijail Gorbachov en la ex Unión Soviética a finales de los años ochenta y que se conjugaron con otra serie de renovadores desde el punto de vista económico y político en todo. Estas reformas -conocidas como Perestroika y Glasnost- condujeron a la caída del muro de Berlín, la unificación alemana y el fin de la guerra fría, después de casi cuarenta y cinco años ${ }^{1}$. Un resultado adicional tiene que ver, según el autor precitado, con la transformación de los regímenes totalitarios de Europa Oriental en democracias en lo político y en sistemas capitalistas en lo económico acentuándose, de esta forma, el proceso de globalización económica emprendida por Estados Unidos después de la segunda Guerra Mundial.

La búsqueda de mayores beneficios económicos ha impulsado a los países a crear regiones o mercados multinacionales mediante la reducción de barreras comerciales y arancelarias. En la actualidad, el mundo se encuentra dividido en bloques económicos regionales donde sobresalen por su importancia la Unión Europea, ASEAN, NAFTA y MERCOSUR. Los procesos de integración regional -acuerdos de libre comercio, mercados comunes o uniones económicas- han adquirido en estas últimas décadas mayor dinamismo que en cualquier otro periodo histórico. Los defensores de estos acuerdos señalan que estos mejoran las condiciones de vida de los ciudadanos de los Estados participantes, en tanto que sus detractores apuntan a señalar las profundas divergencias de poder entre ellos y su consecuente derivación en estructuras inequitativas de intercambio.

La mayor interdependencia e intercomunicación que se ha presentado entre los Estados, los individuos y las empresas en las últimas décadas, como ya se dijo, por el uso masivo de las tecnologías de información y comunicación (TIC) y por la voluntad de los países para estrechar sus vínculos comerciales y políticos, no se ha visto reflejado en un mejoramiento en las relaciones diplomáticas y comerciales entre dos naciones con antecedentes históricos comunes como Colombia y Venezuela, debido a la utilización de doctrinas de política exterior y estrategias de inserción inversas que no han facilitado el proceso integrador, hasta el punto que hoy ni siquiera existe un acuerdo de libre comercio entre ambas naciones. 


\section{Respice Polum y Respice Similia}

Respice Polum y Respice Similia son dos expresiones utilizadas en el ámbito de las relaciones internacionales para definir el tipo de estrategia en la política exterior que aplica cada Estado, haciendo énfasis hacia donde van dirigidas las prioridades en su agenda internacional.

La expresión latina Respice Polum fue creada por el estadista colombiano Marco Fidel Suárez en 1914 y hace referencia a la estrategia de "mirar al polo" o "mirar a la estrella polar" que, en el caso de los países latinoamericanos sería "mirar a Estados Unidos". El internacionalista argentino y estudioso de la política exterior colombiana, Juan Tokatlian (1998) argumenta que, desde la pérdida de Panamá en 1903 -alentada por Estados Unidos- la clase dirigente colombiana racionalizó la dependencia de Estados Unidos con la llamada "Doctrina Suárez", que se resume en la conocida frase de quien fue canciller y presidente de nuestro país: "el Norte de nuestra política exterior, debe estar allá en esa poderosa nación que, más que ninguna otra, ejerce atracción hacia los pueblos de América” (Tokatlian, 1998, p 122)

Para Toklatlian, luego de la Segunda Guerra Mundial y desde el comienzo de la Guerra Fría, el Respice Polum se transformó en una visión ideológica del papel de Colombia en el mundo. Así, un férreo anticomunismo y una identificación sin matices con Estados Unidos, caracterizaron la política exterior de Colombia hasta los años setenta del siglo pasado, rasgos que se retomaron casi sin variaciones, en la última década del milenio.

Por su parte Respice Similia hace alusión a la estrategia de "mirar a los similares", que para el caso colombiano sería "mirar a los vecinos", o en el mejor de los casos, “mirar a los países andinos". Durante el gobierno de Alfonso López Michelsen, se intentó configurar una nueva doctrina de política exterior - sustentada en el principio Respice Similia- que buscaba mirar a los países latinoamericanos, especialmente. Desde entonces y hasta el gobierno de Virgilio Barco (1986-1990) la política exterior de Colombia osciló entre esas dos miradas, hacia el Norte y hacia los semejantes. Para Tokatlian, Colombia jamás pretendió ni practicó un des-alineamiento completo de Estados Unidos, sino que intentó, durante este período, un mayor acercamiento a los demás países de la región, sin perder su "norte" convencional.

\section{Colombia mirar a la Estrella Polar: entre dependencia y subordinación}

A partir de los años noventa del siglo pasado, Colombia refuerza su ubicación en el círculo de influencia directa de los Estados Unidos, con la política exterior de los gobiernos de Gaviria (1990-1994), Samper (1994-1998), Pastrana (1998-2002) y Uribe (2002-2010). Analizada la estrategia de Respice Polum emprendida sucesivamente por los presidentes colombianos, el profesor Ricardo Buitrago afirma que: 
“resulta posible señalar que Colombia más que un Estado Andino o Latinoamericano se ha percibido como un país hemisférico inevitablemente influenciado por el poder de los Estados Unidos". (Buitrago, 2007 p. 34)

De igual forma, este autor señala que los gobernantes, desde 1990, han diferido en las tendencias ideológicas, pero han compartido la experiencia de una severa dependencia económica y política de Estados Unidos.

La situación de Colombia, con problemas de inestabilidad interna, con el conflicto interno más antiguo del mundo, convertido en uno de los "patios" de mayor producción de drogas ilícitas -consumidas por los ciudadanos norteamericanos- y en la "sede" de continuas violaciones a los derechos humanos, tanto por parte de agentes del Estado como de los grupos al margen de la ley, ha llevado a que, en épocas recientes, se considere que la garantía de los intereses nacionales se logra a través de una relación subordinada con los Estados Unidos. El país parece suponer que la posibilidad de supervivencia en lo económico, político y militar se ciñe a los supuestos que determinan los gobiernos estadounidenses. Para Socorro Ramírez, los últimos gobiernos colombianos

"han tratado de propiciar una política bilateral con Estados Unidos para enfrentar la situación interna con la política de erradicación y fumigaciones de cultivos de uso ilícito, la modernización de las fuerzas armadas y la respuesta militar a la ofensiva de los grupos irregulares" (Ramírez, 2003 p. 10).

Esta visión se acentuó mucho más durante el gobierno de Álvaro Uribe, en el que los dos principales y controversiales proyectos de la agenda internacional fueron el Tratado de Libre Comercio con Estados Unidos y la instalación de siete bases militares norteamericanas en territorio colombiano, que daba rienda suelta a la más encarnizada estrategia de Respice Polum, al tratar de agradar al país del norte a cualquier costo, sin importar que esto ocasionara el progresivo deterioro de las relaciones con el vecindario. Es interesante hacer notar aquí que, a nivel interno, el desarrollo de la propuesta de "seguridad democrática" en la que se sustentó el gobierno de Uribe, no estuvo muy alejada de los métodos utilizados por el gobierno chavista para consolidar la llamada revolución socialista del siglo XXI en Venezuela. Los dos mandatarios acudieron a cambios en la Constitución Política para mantenerse en el poder y, sobre la base de una imagen mesiánica de redentores de la patria, redujeron los espacios de debate político a su más mínima expresión, a tal punto, que todo aquel que se atreviera a cuestionar la orientación del régimen era acusado en Colombia -y lo sigue siendo hoy en Venezuela- como enemigo de la nación. 


\section{- La era Santos: giro inesperado de estrategia}

Con la llegada de Juan Manuel Santos a la Presidencia de Colombia, la estrategia internacional del Estado colombiano dio un giro inesperado en el camino y se inició una nueva fase de inserción internacional, que le concedió especial preponderancia a la relación con los países latinoamericanos y a la construcción de otros escenarios de cooperación internacional, especialmente con la Región Asia Pacífico, también vecina de nuestro país. Son dos las posibles razones que explicarían el cambio de estrategia de la política exterior colombiana. En primera instancia, la demora y las trabas impuestas en el Congreso de Estados Unidos para la aprobación del Tratado de Libre Comercio entre ambos países, que hicieron visible la necesidad de emprender alianzas estratégicas con otros mercados del mundo. Este tratado, a pesar de ser nefasto para sectores de alto contenido social como el agrícola, había sido la principal apuesta en política exterior de la administración Uribe Vélez en sus ochos años de mandato.

La segunda razón también tiene que ver con la herencia dejada por el gobierno anterior y, esta vez, con el aspecto más negativo de su política exterior, como fue la pésima relación con los países vecinos, especialmente Venezuela, Ecuador, Bolivia y Nicaragua, que terminó por aislar a Colombia y reducir al mínimo su influencia en los escenarios regionales. La relación más candente se planteó con Venezuela, debido a las animadversiones personales entre los gobernantes Chávez y Uribe, generadas por las profundas diferencias ideológicas y por su posición divergente frente a las FARC - guerrilla presente en Colombia desde hace mas de 50 años - cuya persecución se convirtió en la obsesión del presidente colombiano, mientras recibía un trato casi amable en el discurso del mandatario venezolano. Estas diferencias, llevaron a un deterioro casi total en las relaciones bilaterales, con grandes pérdidas para la economía nacional, especialmente la fronteriza.

En estas condiciones, desde el inicio del período presidencial de Santos, la estrategia de Respice Polum fue revaluada por la cancillería colombiana y se emprendió un giro hacia la alternativa de Respice Similium, basada en los buenos oficios de la Ministra de Relaciones Exteriores María Ángela Holguín. Esta nueva estrategia se empezó a vislumbrar desde el momento en que el nuevo mandatario eligió al Brasil como primer destino de visita como Jefe de Estado, dando señales claras de la intención de mejorar las relaciones con sus homólogos cercanos. La segunda gran muestra del cambio de estrategia, se vio con la recomposición de las relaciones comerciales y diplomáticas con Venezuela, rotas durante el gobierno anterior. Estos factores, sumados a la presidencia compartida entre Colombia y Venezuela de UNASUR y al papel jugado por la diplomacia colombiana en el conflicto interno hondureño, le han devuelto un cierto liderazgo regional a nuestro país, perdido cuando se mostraba como un incondicional aliado de los Estados Unidos, por encima de las preocupaciones comunes de los países del sur del continente. 
Por último, una tercera muestra del nuevo aire que han tomado las relaciones internacionales colombianas, se evidencia en la búsqueda de nuevos mercados y de un posicionamiento efectivo en la región Asia-Pacífico, especialmente con los acuerdos comerciales suscritos con los gobiernos de Japón, Corea del Sur, China y la solicitud de ingreso al Foro APEC (Asian Pacific Economic Cooperation).

\section{Venezuela, mirando al similar: entre el Socialismo del siglo XXI y un régimen totalitario}

Durante la mayor parte de la segunda mitad del siglo XX, el desenvolvimiento de Venezuela en la escena internacional estuvo determinado por su condición de nación productora de petróleo. Así, su política exterior se orientó a potenciar esta ventaja comparativa, como lo muestra su participación en la OPEP y el establecimiento de relaciones económicas especiales con otros países productores. Durante el primer gobierno de Carlos Andrés Pérez (1974-1979) se fortalecieron las relaciones con los países miembros del organismo internacional mencionado y se declaró abiertamente la importancia de la riqueza petrolera como herramienta para establecer un nuevo orden económico internacional que permitiera el desarrollo de las naciones del Tercer Mundo.

Durante el segundo mandato de Pérez -entre 1989 y 1993 - la política exterior venezolana se planteó un interesante esfuerzo de re-estructuración para responder al nuevo orden político mundial establecido tras el final de la Guerra Fría. Casi desde el inicio de su gestión, el mandatario emprendió una serie de visitas oficiales a distintos países: Estados Unidos, Hungría, Bolivia, Argentina, Uruguay, Costa Rica, Colombia, Chile, Brasil, España, Francia y la República Federal de Alemania. Pese a este enorme esfuerzo diplomático, Venezuela no pudo desarrollar los lineamientos planeados, que consistían en un nuevo enfoque de la integración latinoamericana, el fortalecimiento de la diplomacia comercial, la cooperación Sur-Sur y el diálogo Norte-Sur.

Según Miguel Ángel Latouche (2007), desde su llegada al poder en el año de 1998, el Teniente Coronel en retiro Hugo Rafael Chávez Frías dejó en claro que su política exterior tendría un tono anti-norteamericano y que trabajaría junto a Estados de similares ideas políticas, encontró el aliado perfecto en Cuba, país con el que tenía relaciones estrechas. Posteriormente, con la paulatina llegada al poder de gobernantes adeptos al Socialismo del siglo XXI, se agudiza su estrategia de Respice Polum, que convirtió a Ecuador, Bolivia, Nicaragua y, más recientemente, a Argentina y Brasil, en sus nuevos aliados en el vecindario y desplazó a Colombia de su histórico papel de socio político y comercial privilegiado. Como se mencionó atrás, en otros hemisferios, la política exterior de la Republica Bolivariana de Venezuela, ha estado orientada al acercamiento con países como Rusia, China e Irán, proveedores del gran armamento adquirido por el ejército venezolano durante los últimos años. 
En este mismo sentido, el internacionalista venezolano Edmundo González Urrutia (2009) argumenta que en los primeros años de su presidencia, Hugo Chávez mantuvo algunas de las líneas básicas de la política exterior de los gobiernos anteriores, basada en la búsqueda de un mayor equilibrio internacional y el impulso a la integración regional. Sin embargo, su consolidación política luego de sus continuos triunfos electorales y, adicionalmente, el aumento del precio del petróleo, le han permitido desplegar una nueva y ambiciosa estrategia internacional. Sin duda, la cancillería de Nicolás Maduro ha jugado un papel fundamental en el retiro de Venezuela de procesos de integración como la CAN, el ingreso al MERCOSUR, el impulso a proyectos como TELESUR, el Banco del Sur y hasta una OTAN Sudamericana. La retórica anti-estadounidense, la compra de armamento y los contactos con China y Rusia son algunos de los elementos más importantes de la segunda etapa de la política exterior chavista.

Sobre la base de estos escenarios, la diplomacia venezolana ha puesto en marcha una estrategia internacional novedosa, de alto perfil estratégico, que tiene como sustento fundamental la variable petrolera. Para muchos expertos, el gobierno de Chávez ha ingresado en una nueva fase, aún más ambiciosa y delicada, que apunta a jugar con variables estratégicas en el tablero geopolítico mundial. Su respaldo abierto a regímenes antidemocráticos como el de Irán o Libia, muestra la faceta más radical de su pensamiento y su capacidad para aliarse con todos aquellos que puedan sumar en oposición a los Estados Unidos y todo lo que representa la potencia del norte.

Latouche plantea que Venezuela, provee a la "aldea global” del recurso estratégico para el buen funcionamiento de la locomotora del sistema y recibe a cambio caudales de divisas, utilizadas para el adoctrinamiento de sus ciudadanos en las ideas socialistas y para aceitar la gran maquinaria electoral que le sirve para legitimarse en el poder en pro del llamado socialismo del siglo XXI. (Latouche, 2007)

Son muchas las críticas que afrontan el Presidente Chávez Frías y su revolución del Siglo XXI. Pero la que más sobresale es que, en el ámbito político, el socialismo del siglo XXI, ha pasado de ser un sistema democrático a un régimen totalitario. Para citar un ejemplo, el periodista venezolano Carlos Ball -presidente del Centro de Divulgación del Conocimiento Económico para la Libertad (Cedice Libertad)considera que, en una sociedad democrática, resulta esencial la existencia de medios de comunicación privados, independientes del poder político y económico. Cuando los principales medios de comunicación están al servicio del proyecto político dominante y obedecen a una sola directriz, desparece la pluralidad y las posibilidades de ejercer la crítica, piezas-clave de todo orden basado en el respeto a las libertades públicas e individuales, el equilibrio entre la sociedad y el Estado y la cooperación entre los poderes (Ball, 2007)

A su vez, Robert Bottome y Norka Parra, afirman que: 


\begin{abstract}
"El presidente Chávez ha radicalizado agresivamente su revolución bolivariana y no es socialista ni comunista verdadero, sino un déspota que no se detendrá en su objetivo de subyugar al pueblo venezolano a través de la erradicación de la libertad de expresión, libre empresa y derecho a la propiedad privada, y en la concentración de todo el poder civil y económico en manos del Presidente vitalicio (él)” ( Bottome y Parra, 2007 p.11).
\end{abstract}

Por su parte, la comisión de derechos humanos de la OEA investiga unos 780 casos de discriminación política en Venezuela. El gobierno ha compilado una lista de 12.4 millones de opositores, conocida como la Lista Maisanta, que utiliza para negarles empleos gubernamentales, licencias o pasaportes. (Oppenheimer, 2008). De igual manera, fueron despedidos todos los trabajadores de la empresa estatal de petróleos (PDVSA) que hicieron parte de las huelgas petroleras en contra del gobierno chavista. Es evidente que no hay igualdad de derechos para la totalidad de la población, viéndose beneficiados únicamente los adeptos a la revolución oficialista.

Otro tema que preocupa a varios analistas internacionales es el anuncio y la implementación de la nacionalización de compañías del sector eléctrico, comunicaciones y energético entre las que se destacan la compañía telefónica CANTV, la Siderúrgica del Orinoco (Sidor), las empresas eléctricas (Electricidad de Caracas, Electricidad de Valencia y Séneca) que causa inmediatamente la marcha de inversionistas extranjeros de Venezuela y una devaluación de la moneda Venezolana (Bolívar). Se espera el anuncio de estatización de más empresas estratégicas en el manejo de la economía venezolana para, de esta manera, radicalizar aún más el modelo económico socialista. Se puede concluir, entonces, que durante el régimen político del Presidente Hugo Chávez Frías, comprendido entre los años 1998 y 2012, se ha desarrollado una democracia restringida donde el poder político, legislativo, judicial, económico ha sido concentrado progresivamente en manos de una sola persona y de un partido político único, que ejerce el control de todas las esferas y en el que la oposición está proscrita.

\title{
A manera de conclusión
}

Aún a pesar que la imagen de la "aldea global" remite a un mundo sin fronteras en el que las relaciones diplomáticas y los tratados comerciales y geopolíticos se convertirían en los instrumentos por excelencia para el acercamiento entre los Estados, la experiencia reciente de Colombia y Venezuela nos muestra perspectivas muy diversas respecto a los potenciales alineamientos para jugar en los escenarios globalizados, de tal forma que hoy, paradójicamente, existen menos puntos de contacto entre esto dos países, considerados por mucho tiempo como socios naturales y países hermanos por excelencia. 
Según se ha planteado en el artículo, en el fondo de la cuestión está una concepción diferente de relaciones internacionales, ya que Colombia aún centra su atención en el eje norteamericano, aún a pesar de los esfuerzos del gobierno actual por disminuir los factores de controversia con los países vecinos - como lo demuestra su reciente posición en el Consejo de Seguridad de las Naciones Unidas frente al conflicto entre Israel y Palestina- en tanto el país vecino le apuesta a conjugar esfuerzos y voluntades entre los latinoamericanos con el fin de deslindarse progresivamente de las directrices estadounidenses y generar un polo alterno de poder en el que el recurso petrolero pueda jugar un papel estratégico.

Así las cosas, se requiere de grandes esfuerzos diplomáticos y de proyectos económicos concretos en los que se conjuguen los intereses de los dos países, para disminuir las tensiones derivadas de los enfoques ideológicos diversos y hacer realidad el restablecimiento pleno de las relaciones bilaterales. En el escenario futuro, le corresponde no sólo al gobierno liderar iniciativas renovadoras para recomponer la desconfianza mutua que nos ha dejado casi una década de "tire y encoje", sino que el sector empresarial y los actores gremiales y sociales deben asumir un papel protagónico para recuperar y potenciar las relaciones con un socio que cuenta, no sólo con un mercado valioso para la orilla colombiana, sino con recursos estratégicos de dimensiones enormes que, sumados a los colombianos, podrían jugar un papel definitivo en los proyectos de inserción positiva en los escenarios internacionales de las dos naciones suramericanas.

Lo anterior significa que la política exterior de Colombia y Venezuela no puede mantener más su pretensión mono-céntrica. Es necesario permitir la heterogeneidad sobre los entes, agentes y organizaciones que participan en su construcción. Ante las nuevas realidades a los cuales se han visto avocadas las relaciones binacionales, los gobiernos de Colombia y Venezuela deben ser más audaces en el planteamiento de alternativas que estén encaminadas hacia una mayor integración estratégica en los campos comercial, político y cultural.

\section{REFERENCIAS BIBLIOGRÁFICAS}

Amadeo, M (1978) Manual de política Internacional; Abeledo-Perrot; Buenos Aires

Ardila, M. (2002) Prioridades y desafíos de la política exterior de Colombia, Bogotá, Fescol - Hans Seidel Sttufung

Boron, A. (2008) Tiempos Violentos. Buenos Aires. Mc Graw Hill.

Buitrago, R. (2009) "La dependencia de la política exterior: una visión teórico práctica desde la apertura económica”. Revista Vox Populi. 
Campanella, B. (2002) Política Internacional del Siglo XX, Ed. De Belgrano, Buenos Aires

Cato Institute. Ball, Carlos, "Socialismo del siglo XXI". http://www.elcato. org/ node/2218

Cato Institute. Robert Bottome y Norka Parra. "Totalitarismo del Siglo XXI". 17 de Enero de 2007 http://www.elcato.org/node/2165

Ceballos, A. (2009) "La Era de las Oportunidades” Revista Gerente, Febrero

Chomsky, N. (1996). El nuevo orden mundial (y el viejo). Barcelona: Crítica

Díaz Mier (2009) Negocios Internacionales, Ediciones Pirámide, Bogotá.

Del Arenal, A (2005) Introducción a las relaciones internacionales. Madrid: Tecnos.

Casal F (2003) "Hugo Chávez Frías: ¿Hacia una nueva política exterior venezolana? "http://www.rlcu.org.ar/revista/numeros/01-01-Octubre-2003/documentos/ fernando_casal.pdf consulta de octubre 12 de 2011

Gutiérrez Pantoja, Gabriel, (2005) Enfoques conceptuales contemporáneos, Teoría de las Relaciones Internacionales, Oxford University Press-Harla, México

Hill, C. (2008) Negocios Internacionales en un mundo global. E d., Mac Graw Hill. Buenos Aires.

Lautoche, M. (2007) "Democracia y política exterior en Venezuela: Desafíos y tendencias". Revista Politeia.

MacLuhan M. (1967) El medio es el mensaje. Ed. Plaza y Janés. 1967

Mesa R. (1977) Teoría y Práctica de las Relaciones Internacionales Madrid, Tecnos.

Morgenthau, Hans J., (1986) Política entre las naciones, la lucha por el poder y la paz, Grupo Editor Latinoamericano, Buenos Aires

Nevis, Allan, et Al., (1996) Breve historia de los Estados Unidos, Fondo de Cultura Económica, México.

C. Ominami, (2003) La Tercera Revolución Industrial: impactos internacionales del nuevo patrón tecnológico, Buenos Aires, Rial.

Palomares, G. (2006) Relaciones Internacionales en el siglo XXI. 2 Ed. Ed. Tecnos. Madrid. 2006

Person F, Rochester M. (2006) Relaciones Internacionales, Situación Global en el S. XXI. Mc Graw Hill, Bogotá

Ramírez, S. (1999) Colombia y Venezuela: agenda común para el siglo XXI, Bogotá, Instituto de Estudios Políticos y Relaciones Internacionales (IEPRI) Universidad Nacional de Colombia. 
Ramírez, S (2003) "Las relaciones exteriores de Colombia y Venezuela desde una perspectiva hemisférica" Instituto de Estudios Políticos y relaciones Internacionales de la Universidad Nacional de Colombia, Bogotá.

Ramírez S. y Cadenas J (2003) La vecindad colombo-venezolana: imágenes y realidades, Grupo Académico Colombia Venezuela, Instituto de Estudios Políticos y Relaciones Internacionales (IEPRI) de la Universidad Nacional de Colombia - Universidad Central de Venezuela (UCV) - Convenio Andrés Bello (CAB).

Restrepo, L. (1999) Estados Unidos. Potencia y prepotencia, Santa Fe de Bogotá: Tercer Mundo Editores/Instituto de Estudios Políticos y Relaciones Internacionales, Universidad Nacional/DNP.

Tamames, Ramón, (1999) Estructura económica internacional, Alianza, núm. ed. 19, España.

Toro Ardí, A. (2007) Hegemonía e imperio. Bogotá: Villegas Editores.

Tokatlian, J. (1998) Colombia y Estados Unidos: problemas y perspectivas, Santa Fe de Bogotá: Tercer Mundo Editores/Instituto de Estudios Políticos y Relaciones Internacionales, Universidad Nacional/ COLCIENCIAS

Villegas, G. (2001) Cuando América completó la tierra. Bogotá D.C. Villegas Editores. 



\section{DIVISIÓN DE CIENCIAS ECONÓMICAS, ADMINISTRATIVAS Y CONTABLES UNIVERSIDAD SANTO TOMÁS- BUCARAMANGA}

\section{PAUTAS PARA COLABORADORES}

La Revista Lebret de la División de Ciencias Económicas, Administrativas y Contables de la Universidad Santo Tomás, Indexada en Categoría C de Publindex, Colciencias, considera la publicación de trabajos inéditos que aporten a las áreas de las ciencias sociales, en particular la economía, la administración y la contaduría. Estos textos deben ser producto de investigaciones realizadas:

1. proyectos finalizados de investigación científica (Artículos de Investigación): documento que presenta los resultados originales de proyectos de investigación y muestra de manera rigurosa los referentes conceptuales y metodológicos utilizados y las conclusiones a las que se llega,

2. reflexiones analíticas sobre un problema particular, con base en fuentes originales (Artículos de Reflexión): documento que presenta resultados de investigación finalizada, desde una perspectiva analítica, interpretativa del autor, sobre un tema específico,

3. revisiones bibliográficas (Artículo de Revisión): documento de investigación terminada donde se analizan los resultados de investigaciones publicadas o sin publicar, sobre un campo específico, para dar cuenta de las tendencias y avances del mismo mediante por lo menos cincuenta referencias.

La revista incluirá también reseñas de libros en español o traducciones que no hayan sido publicados en otras revistas.

El autor debe adjuntar el formato de Hoja de Vida o un resumen de la hoja de vida que señale sus títulos académicos, cargos desempeñados, publicaciones recientes (nombre de la publicación, especificar si tiene un grado de indexación) y un número de teléfono y correo electrónico. El artículo y los archivos adjuntos se reciben en las siguientes direcciones electrónicas: revistalebret@gmail.com o revistalebret@mail. ustabuca.edu.co. 
Se solicita al autor especificar acerca del artículo: subárea del conocimiento del texto que envía, el nombre del proyecto de investigación del cual se deriva el artículo, el nombre de la entidad que financia dicha investigación y la fecha en la cual fue iniciado y terminado dicho proyecto.

\section{Otras indicaciones}

1. Las contribuciones deben se inéditas, presentadas en formato Word, cuadros y gráficos en Excel, versión office 2003, con claridad en las convenciones. Los archivos deben señalar el lugar y página donde se insertan los cuadros y gráficos o especificar los cuadros anexos. Las imágenes o mapas deben tener una resolución de por lo menos 300 dpi y estar en formato .tif o .jpg.

2. Los trabajos tendrán una extensión entre 5.000 y 10.000 palabras, tamaño carta, incluidas notas y referencias bibliográficas; la letra Times New Roman 12 puntos, interlineado doble espacio y márgenes izquierdo de $4 \mathrm{~cm}$ y $2,5 \mathrm{~cm}$ en la parte superior, inferior, derecha de cada página.

3. Las reseñas de libros publicados no pueden exceder las 1.200 palabras.

4. La extensión del resumen en español e inglés debe tener entre 6 y 10 líneas. El autor especificará tres o cuatro palabras claves.

5. Los artículos deben ser originales, con redacción clara, precisa e impersonal.

6. El título del artículo debe ser preciso y exponer el tema del trabajo.

7. El resumen del artículo debe estar redactado en tercera persona y en tiempo presente. Contiene: la pregunta, el marco teórico, la metodología, los principales hallazgos y las conclusiones.

8. Las notas a pie de página se emplearán para hacer aclaraciones o explicitar datos adicionales, deben aparecer numeradas y ser los más breves posibles.

9. En las citas textuales menores de 40 palabras, el párrafo citado irá entre comillas, en el cuerpo del texto. Las citas textuales con más de 40 palabras, comienzan en un nuevo renglón con una sangría de 5 espacios en el margen izquierdo y sin comillas.

10. Las citas bibliográficas se realizarán en el cuerpo del texto entre paréntesis.

Por ejemplo (apellido, año) en citas textuales se agrega la página (apellido, año, p.) Ejemplo: (González, 2008, p. 65).

11. Para citar un estudio elaborado por más de 2 personas y menos de 6 debe escribirse el apellido de todos los autores. Si la cita va al inicio del párrafo, por ejemplo: Therán, González, Prada y Botache (2004) encontraron que los factores de rendimiento de las frutas dependen de la calidad del suelo. Al final 
del párrafo por ejemplo: los factores de rendimiento de las frutas dependen de la calidad del suelo (Therán, González, Prada y Botache, 2004). En adelante, cada vez que se mencione el texto de estos autores se escribirá el apellido del primer autor, seguido por la expresión et al. y la fecha.

12. Las citas de periódicos deben ser incorporadas dentro del texto entre paréntesis así: Titulo de la fuente, día mes año, página.

13. Las referencias bibliográficas completas van al final del texto, como bibliografía, por orden alfabético según el apellido del autor. Se denomina referencias bibliográficas, en cambio de bibliografía, estas deben corresponder con el número de citas. Así:

a. Libros: apellidos e iniciales del nombre de los autores; año de la edición utilizada, título del libro en cursiva, ciudad de la publicación, país: casa editora, (año de la publicación original, si la obra ha tenido varias ediciones). Ejemplo: Therán, C. (1997). La productividad en la manufactura, Bogotá, Colombia: Fondo de Cultura Económica. Si la obra ha tenido varias ediciones: Carmen Therán, 1997, la productividad en la manufactura, Bogotá: Fondo de Cultura Económica, 2000.

b. Artículos: apellidos e iniciales de los nombres de los autores, año de la publicación, título del artículo, nombre de la revista y volumen (si tiene) en cursiva, número, páginas del artículo. Ejemplo: Botache, R. (2001). Mercado de tierras. Cife, 56, 31-36.

c. Capítulos de libro: Autor, (año), título del capítulo, en nombre de editores, nombre de libro en cursiva, páginas del capítulo, ciudad, país: editorial. Ejemplo: Gómez, E., Linares, H. (2001). Técnicas de contabilidad y negocios internacionales. En Santos J. y Albarracín G. (Eds). Finanzas internacionales (pp. 409-500). Bucaramanga, Colombia: Tres Culturas.

d. Los trabajos sin autor: Se incluyen solamente si es importante para el texto y se escribe entre comillas el nombre del libro; por ejemplo: ("Constitución Política de Colombia”, 1991) es una referencia usada para citar decretos y leyes.

e. Las citas de un autor que cita a otro autor debe corresponder en referencias con el texto de quien hace la cita. En el cuerpo del texto se cita el autor, paréntesis, año, citados en apellido, año. Por ejemplo: al comienzo del texto: Rojas y Linares (1996 citado en Mantilla, González y Botache, 2000). Al final del texto (Rojas y Linares, 1996 citado en González \& Botache, 2000).

f. Documentos en sitio Web de una organización: Apellido, inicial de nombre. (año), título del texto en cursiva. Recuperado el día, mes año, del sitio Web (nombre del sitio Web): dirección virtual. Ejemplo: Caviedes, E. (2001). La administración actual. Recuperado el 13 de agosto de 2008, del sitio Web de 
la Asociación Colombiana de Administración: http://www.acad.or/detalle/06/ id.doc1-colombia-pdf.

\section{Proceso de selección de contribuciones}

Los documentos se recibirán mediante convocatoria abierta a la comunidad académica nacional, regional e institucional, estableciendo un tiempo límite para su recepción. Los artículos seleccionados por el Comité Editorial, serán sometidos a la evaluación por dos expertos, quienes dispondrán de un mes para emitir su concepto.

La revista dispone de una base de datos de pares internos y externos a la institución para la evaluación de cada uno de los artículos. El proceso de evaluación es confidencial, pero los comentarios de los artículos se remitirán a los autores, con las sugerencias pertinentes del Comité Editorial de la revista, en caso de requerir ajustes.

La revista establecerá un seguimiento editorial, con la fecha de recepción y aprobación de cada uno de los artículos; el diligenciamiento de formato de evaluación (calidad, originalidad e importancia del texto) por cada uno de los evaluadores, quienes emitirán su concepto a través de una calificación y valoración del texto. La decisión de publicación de artículos corresponde al Comité Editorial.

\section{Licencia para la publicación de artículos}

El autor autorizará a la Revista Lebret la publicación del artículo en su versión impresa o electrónica. Con las siguientes condiciones:

En caso de obras colectivas, quien firma actúa en nombre de los coautores, y debe haberles informado previamente los términos de esta autorización.

De igual manera el o la autor (a) certifica y acepta que:

(a) Dicho artículo no ha sido publicado, ni aceptado para publicar en otras revistas. (b) En caso de haber sido reportada la publicación de una versión previa como

'literatura gris' o en un sitio web, y que en caso de ser publicada por la Revista Lebret, será retirada del sitio de internet, en el que se dejará sólo el título, el resumen, las palabras clave y el hipervínculo a la Revista Lebret. 


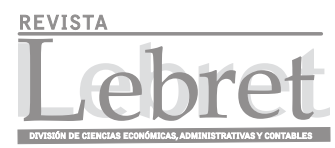

\section{DIVISION OF ECONOMICS, ADMINISTRATIVE AND ACCOUNTING UNIVERSIDAD SANTO TOMAS BUCARAMANGA - COLOMBIA GUIDELINES FOR CONTRIBUTORS}

Revista Lebret is a journal of the Division of Economics, Management and Accounting from the University of Santo Tomás considers unpublished works that contribute to the areas of social sciences, in particular, results of research on economics, administration and accounting. The journal welcomes criteria Colciencias-Publindex for scientific articles:

1. Paper that presents original research results and shows rigorously the conceptual and methodological references used and the conclusions reached,

2. reflection Article: analytical reflections on a particular issue, based on original scientific work, document that presents results of final research, from an analytical perspective, interpretation of the author on a specific topic,

3. review Article: literature reviews of a final research. This paper analyzes the results of published and unpublished research on a specific field, to account for trends and developments of the same through at least fifty references.

The author should attach a summary of the resume outlining your qualifications, positions held, recent publications and email. The article and the attachments are received at the following address: revistalebret@gmail.com. The receipt of goods takes place from April 30 of each year. Guidelines for articles:

1. Contributions should be unpublished, submitted in Word, tables in Excel and graphics, images or maps should have a resolution of at least $300 \mathrm{dpi}$ and be Tif or Jpg. The files must indicate the site and page where pictures and graphics inserted or specify the schedules.

2. The work will have a length between 5,000 and 10,000 words, including notes and references, letter muss be Times New Roman size the 12 point, doublespaced line spacing and margins of $4 \mathrm{~cm}$ left and $2.5 \mathrm{~cm}$ at the top, bottom, right of each page. 
3. Book reviews published may not exceed 1,200 words.

4. The abstract in Spanish and English must be between 6 and 10 lines. The author specifies three or four keywords.

5. Articles must be original, with clear writing, precise and impersonal.

6. The title should be precise and explain the theme of work.

7. The summary of the article should be written in third person and present tense. It should contain the question, the theoretical framework, methodology, key findings and conclusions.

8. The footnotes on the page will be used to clarify or explain further data should appear to be numbered and the shortest possible.

9. References, quotes, other quotes, charts, should follow the APA convention for scientific articles.

\section{Selection process for contributions}

The papers will be received by open call to the academic community, on the international, national regional and institutional levels, setting a time limit for acceptance. The articles selected by the Editorial Committee, will be subject to evaluation by experts, who have one month to issue its concept.

The magazine has a database of internal and external advisors to the institution for the evaluation of each article. The evaluation process is confidential, but the comments of the articles are sent to authors with relevant suggestions and require adjustments of the Editorial Committee if is the case.

The decision to publish articles corresponds to the Editorial Committee. Who will establish a follow-up, depends of the date of receipt and approval of each of the articles, filling out evaluation forms of quality, originality and importance of the text, also for each of the advisors, who give their concept through a classification and valuation of the text. 


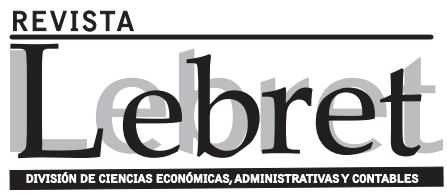

\section{CUPON DE SUSCRIPCIÓN}

\begin{tabular}{|l|}
\hline \multicolumn{1}{|c|}{ SUSCRIPTORES } \\
\hline Nombres \\
\hline Apellidos \\
\hline
\end{tabular}

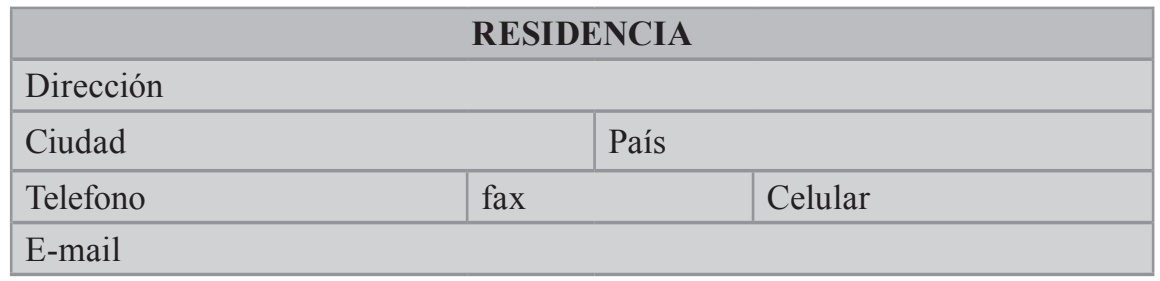

\section{SUSCRIPCIÓN ANUAL}

\begin{tabular}{l|l} 
Colombia $\$ 10.000$ & Exterior: US $\$ 5$
\end{tabular}

\section{SUSCRIPCIÓN A PARTIR DEL NÚMERO}

\section{ESTIMADO SUSCRIPTOR}

- Consigne en la cuenta de ahorrros número 184-91-706-0 del Banco de Bogotá a nombre de Universidad Santo Tomás

- Envie copia del recibo de consignación, junto con este cupon a la División de Ciencias Económicas y Contables de la Universidad Santo Tomás en la carrera 18 №9-27 Bucaramanga o copia a revistalebret@gmail.com 